\title{
Uji Stabilitas pH dari Daun Mangga Hasil Ekstraksi Dengan Menggunakan Metode Spektrofotometer
}

\author{
Kartika Dian Elliana dan R.T.D. Wisnu Broto* \\ Program Studi Teknik Kimia, Departemen Teknologi Industri, Sekolah Vokasi, Universitas Diponegoro \\ Jl. Prof. Soedarto, Tembalang, Kota Semarang, Jawa Tengah 50275, Indonesia \\ Email : vieshnoe@gmail.com
}

\begin{abstract}
Abstrak
Untuk mengetahui stabilitas reduksi klorofil hasil ekstraksi berupa ekstrak dan rafinat, pada penelitian ini dilakukan ekstraksi klorofilid dari daun mangga, menggunakan alat ekstraktor berpengaduk. Daun mangga dipotong $1 \mathrm{~cm}$, selanjutnya di ekstraksi dengan menggunakan pelarut Aquadest 25\%:75\% Isopropil Alkohol. Ada beberapa faktor yang menentukan dalam proses ekstraksi, antara lain pemilihan pelarut. Pada penelitian ini menggunakan spektrofotometer dengan tujuan untuk mengetahui absorbansi klorofil optimum dalam suatu variabel ekstrak dan rafinat, untuk mengetahui stabilitas $\mathrm{pH}$ yang baik untuk mereduksi klorofil daun mangga, maka dilakukan uji $\mathrm{pH}$. Hasil absorbansi klorofil optimum pada suhu $60^{\circ} \mathrm{C}$, waktu 70 menit pada ekstrak dan hasil stabilitas $\mathrm{pH}$ untuk mereduksi klorofil didapatkan pada pH 9 basa serta $\mathrm{pH} 2$ asam.
\end{abstract}

Kata kunci : Ekstrakstor berpengaduk, Daun Mangga, Aquadest, Isopropil Alkohol

\section{Abstract \\ pH Stability Test from Mango Leaf extracted using the SpectropHotometer}

To determine the stability of chlorophyll reduction extracted in the form of extracts and raffinates, chlorophyllid extraction from mango leaves was carried out in this study using a stirred extractor. Mango leaves are cut by 1 $\mathrm{cm}$, then extracted using Aquadest 25\%: 75\% Isopropyl Alcohol. There are several determining factors in the extraction process, including the selection of solvents. In this study using a spectrophotometer with the aim to determine the optimum chlorophyll absorbance in an extract and rafinat variable, to determine good $\mathrm{pH}$ stability to reduce mango leaf chlorophyll, $\mathrm{pH}$ testing was carried out. The optimum chlorophyll absorbance at 60OC, 70 minutes in extract and $\mathrm{pH}$ stability results to reduce chlorophyll were obtained at $\mathrm{pH} 9$ bases and $\mathrm{pH}$ of 2 acid.

Keywords : Stirred Extractor, Mango Leaves, Aquadest, Isopropyl Alcohol

\section{PENDAHULUAN}

Tanaman mangga (Mangifera indica I) berasal dari India (Chonhenchob et al., 2011 ). Gen, hormon, struktur anatomi dan morfologi organ tumbuhan serta kandungan klorofil merupakan faktor petumbuhan (Sasmitamihardja dan Siregar, 1996). Adanya pigmen berwarna hijau yang terdapat dalam kloroplas disebut klorofil (Salisbury dan Ross, 1995). Proses fotosintesis pada daun terjadi di kloroplas. Energi cahaya diubah menjadi energi kimia dalam bentuk adenosin trifosfat (ATP) oleh pigmen pada membran tilakoid (Sumenda, 2011).

Pada daun mangga mengandung klorofil, diekstraksi menggunakan pelarut. Setelah tercapai kesetimbangan, ekstraksi dihentikan, selanjutnya pelarut dipisahkan dari sampel dengan penyaringan. Klorofil merupakan senyawa ester, larut dalam solvent organik (Arrohmah et al., 2017; 
Chew et al., 2011; Andres et al., 2014). Dengan demikian variabel suhu dan variabel waktu dengan pelarut Isopropil Alkohol 75\% : 25\% Aquadest tetap digunakan dalam proses ekstraksi daun mangga menggunakan ekstraksi berpengaduk. Hasil yang akan diamati yaitu kandungan klorofil pada hasil ekstrak dan rafinat dengan metode ekstraksi menggunakan analisa spektrofotometri (Hu et al., 2013). Proses ekstraksi dihentikan ketika tercapai kesetimbangan antara konsentrasi senyawa dalam pelarut dengan konsentrasi dalam sel tanaman (Darma dan Kito 2014). Melakukan analisa spektrofotometri pada panjang gelombang maksimum yang memberikan absorbansi maksimum (Ati et al., 2006; Casas et al., 2009; Senguttuvan et al., 2014)

Kandungan klorofil bersifat tidak stabil dan lebih mudah rusak bila terkena sinar, panas, asam dan basa. Dengan demikian variabel suhu dan variabel waktu dengan pelarut Isopropil Alkohol $75 \%$ : 25\% Aquadest tetap digunakan dalam proses ekstraksi daun mangga menggunakan ekstraksi berpengaduk. Hasil yang akan diamati yaitu kandungan klorofil pada hasil ekstrak dan rafinat dengan metode ekstraksi menggunakan analisa spektrofotometri untuk mengetahui zat warna klorofil dan analisa asam basa menggunakan $\mathrm{PH}$ meter untuk mengetahui stabilitas klorofil pada daun mangga.

\section{METODOLOGI}

Tahap awal dengan persiapan bahan daun mangga dan pemotongan daun $1 \mathrm{~cm}$. Setelah itu daun mangga diekstraksi menggunakan variable perbandingan Isopropil alkohol : Aquadest 75\%:25\%. Langkah selanjutnya diekstraksi dengan perubahan suhu yaitu $45^{\circ} \mathrm{C}, 50^{\circ} \mathrm{C}, 55^{\circ} \mathrm{C}, 60^{\circ} \mathrm{C}$ dan $65^{\circ} \mathrm{C}$ sehingga didapatkan suhu optimum. Setelah didapatkan suhu optimum maka dengan menggunakan suhu optimum itu dilanjutkan dengan ekstraksi perubahan waktu yaitu 30, 40, 50, 60 dan 70 menit sehingga didapatkan suhu dan waktu optimum hasil ekstraksi daun mangga. Dilakukan pengujian untuk absorbansi menggunakan spektrofotometer dengan panJang gelombang $436 \mathrm{~nm}$.

Tahap berikutnya dilanjutkan dengan menguji stabilitas ekstrak dan rafinat daun mangga terhadap efek $\mathrm{pH}$. Dalam uji stabilitas klorofil $\mathrm{pH}$ dilakukan pada $\mathrm{pH}$ asam dan $\mathrm{pH}$ basa setiap percobaan dilakukan 5 kali pada situasi basa atau asam.

\section{HASIL DAN PEMBAHASAN}

Menggunakan metode ekstraksi berpengaduk, Isopropil Alkohol 25\% berbanding aquadest $75 \%$ sebagai solvent tetap. Sampel yang digunakan adalah daun mangga yang telah di potong kecil-kecil $1 \mathrm{~cm}$ dengan 2 variabel yaitu perbandingan suhu dan perbandingan waktu. Setiap Variabel akan dilakukan 5 percobaan. Langkah pertama yang dilakukan yaitu daun mangga yang sudah dipotong-potong dimasukkan kedalam ekstraktor berpengaduk dengan penambahan solvent, lalu dilakukan 5 kali percobaan dengan suhu yang berbeda, yaitu $(45,50.55,60$ dan 65$){ }^{\circ} \mathrm{C}$.

Perbedaan suhu hasil ekstraksi dengan 5 kali percobaan $\mathrm{pH}$ berbeda pada penambahan 1-5 tetes $\mathrm{NaOH}$ pH basa dan $\mathrm{HCl}$ pH asam dihasilkan pada penambahan $\mathrm{NaOH}$ yaitu $\mathrm{pH}$ basa stabil pada 9 dan $\mathrm{pH}$ asam stabil pada 2 (Gambar 1). Pada hal ini stabilitas $\mathrm{pH}$ asam dapat mereduksi klorofil pada pH 2 menunjukkan percobaan $145^{\circ} \mathrm{C}$ 1,392, percobaan $250^{\circ} \mathrm{C} 0,906$, percobaan $355^{\circ} \mathrm{C}$ 0,836 , percobaan $460^{\circ} \mathrm{C} 1,450$, dan percobaan 5 $65^{\circ} \mathrm{C} 1,357$, dan $\mathrm{pH}$ basa dapat mereduksi klorofil pada $\mathrm{pH} 9$ percobaan $145^{\circ} \mathrm{C} 1,119$, percobaan 2 $50^{\circ} \mathrm{C} 1,329$, percobaan $355^{\circ} \mathrm{C} 1,184$, percobaan 4 $60^{\circ} \mathrm{C} 1,977$, dan percobaan $565^{\circ} \mathrm{C} 1,607$. Hal ini menunjukkan bahwa pada $\mathrm{pH} 2$ dan 9 ekstrak dapat mereduksi klorofil. Dan klorofil optimum pada suhu $60^{\circ} \mathrm{C}$ didapatkan hasil grafik yang optimum hal ini menunjukkan bahwa hasil ekstraksi yang optimum akan mendapatkan hasil klorofil yang optimum juga. Sudah sesuai dengan teori bahwa semakin tinggi konsentrasi larutan maka semakin tinggi nilai absorbansinya (Milenković et al., 2012).

Hasil ekstraksi dengan 5 kali percobaan $\mathrm{pH}$ berbeda pada penambahan 1-5 tetes $\mathrm{NaOH}$ pH basa dan $\mathrm{HCl} \mathrm{pH}$ asam dihasilkan pada penambahan $\mathrm{NaOH}$ yaitu $\mathrm{pH} 9$ sedangkan pada penambahan $\mathrm{HCl}$ yaitu $\mathrm{pH} 2$ (Gambar 2). Pada 3-5 tetes $\mathrm{NaOH}$ dan $\mathrm{HCl}$ didapatkan $\mathrm{pH}$ yang stabil yaitu $\mathrm{pH} 9$ dan $\mathrm{pH}$ 2. Pada hal ini stabilitas $\mathrm{pH}$ asam dapat mereduksi klorofil pada $\mathrm{pH} 2$ 
menunjukkan percobaan 630 menit 1,450, percobaan 740 menit 1,379 , percobaan 850 menit 1,360, percobaan 960 menit 1,044, dan percobaan 1070 menit 1,422, dan $\mathrm{pH}$ basa dapat mereduksi klorofil pada $\mathrm{pH} 9$ percobaan 630 menit 1,977, percobaan 740 menit 1,757, percobaan 850 menit 1,605, percobaan 960 menit 1,245, dan percobaan 1070 menit 1,919. Hal ini menunjukkan bahwa pada $\mathrm{pH} 2$ dan 9 ekstrak dapat mereduksi klorofil. Pada waktu 60 menit hasil rafinat menurun menunjukkan bahwa zat-zat yang terdapat dibahan telah terambil oleh pelarut menjadi larutan ekstrak. $\mathrm{pH}$ mempengaruhi konsentrasi absorbansi pada uji analisa spektrofotometer (Putriantari dan Santosa 2014)

Hasil rafinat dengan 5 kali percobaan $\mathrm{pH}$ berbeda pada penambahan 1-5 tetes $\mathrm{NaOH} \mathrm{pH}$ basa dan $\mathrm{HCl} \mathrm{pH}$ asam dihasilkan pada penambahan $\mathrm{NaOH}$ 3-5 tetes yaitu $\mathrm{pH}$ stabil pada $\mathrm{pH} 9$ dan pada penambahan $\mathrm{HCl} 3-5$ tetes $\mathrm{pH}$ stabil pada $\mathrm{pH} 2$ (Gambar 3). Dikarenakan dengan menggunakan sampel hasil ekstraksi yang sama maka $\mathrm{pH}$ rafinat dan $\mathrm{pH}$ ekstrak juga sama. Pada hal ini stabilitas $\mathrm{pH}$ asam yang terdapat pada rafinat dengan sebagian klorofil masih terikut kedalam rafinat sehingga hasil absorbansi menunjukkan pada $\mathrm{pH} 2$ menunjukkan percobaan $145^{\circ} \mathrm{C} 0,286$, percobaan $250^{\circ} \mathrm{C} 0,751$, percobaan $355^{\circ} \mathrm{C}$ 0,669, percobaan $460^{\circ} \mathrm{C}$ 0,650, dan percobaan $565^{\circ} \mathrm{C}$ 0,655, dan $\mathrm{pH}$ basa dapat mereduksi klorofil pada $\mathrm{pH} 9$ percobaan $145^{\circ} \mathrm{C}$ 0,782 , percobaan $250^{\circ} \mathrm{C} 0,865$, Percobaan $355^{\circ} \mathrm{C}$ 0,999; percobaan $460^{\circ} \mathrm{C} 0,981$, dan percobaan 5 $65^{\circ} \mathrm{C} 0,990$. Hal ini menunjukkan bahwa pada $\mathrm{pH} 2$ dan 9 rafinat dapat mereduksi klorofil optimum.

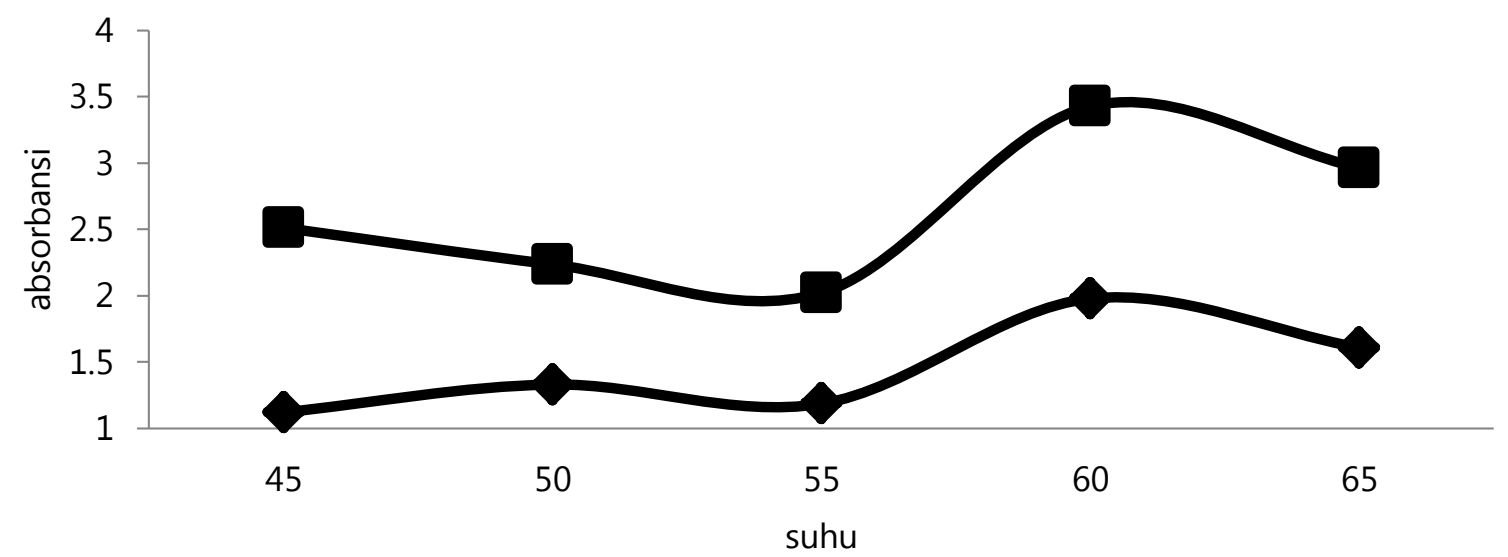

Gambar 1. Pengaruh kenaikan suhu terhadap absorbansi stabilitas pH ekstrak Keterangan. $\boldsymbol{W}=$ asam, basa

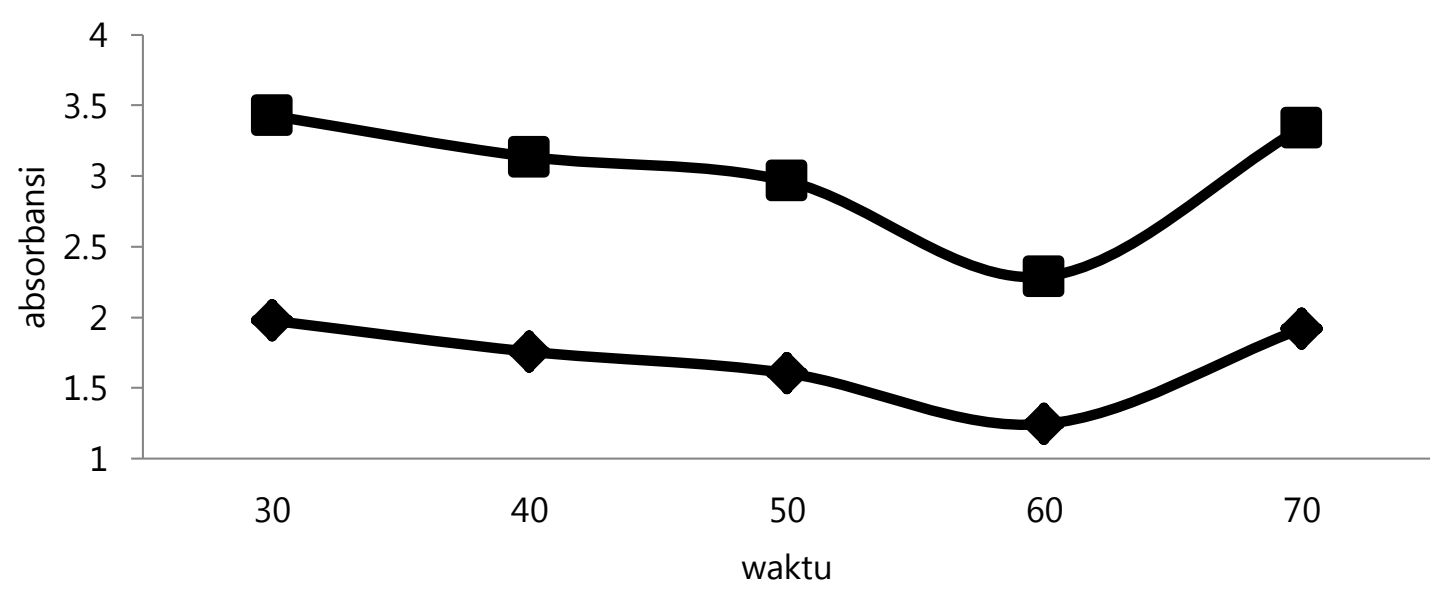

Gambar 2. Pengaruh perubahan waktu terhadap absorbansi stabilitas pH ekstrak Keterangan.

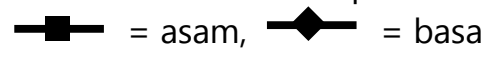




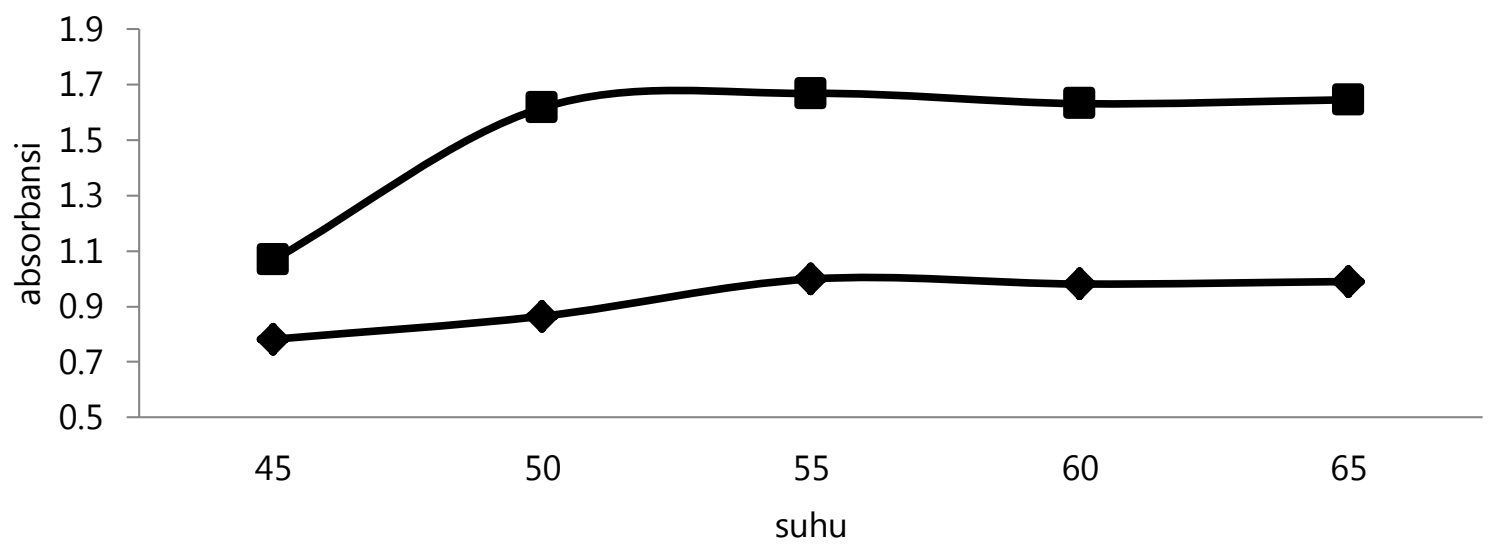

Gambar 3. Pengaruh kenaikan suhu terhadap absorbansi rafinat perbedaan suhu Keterangan.
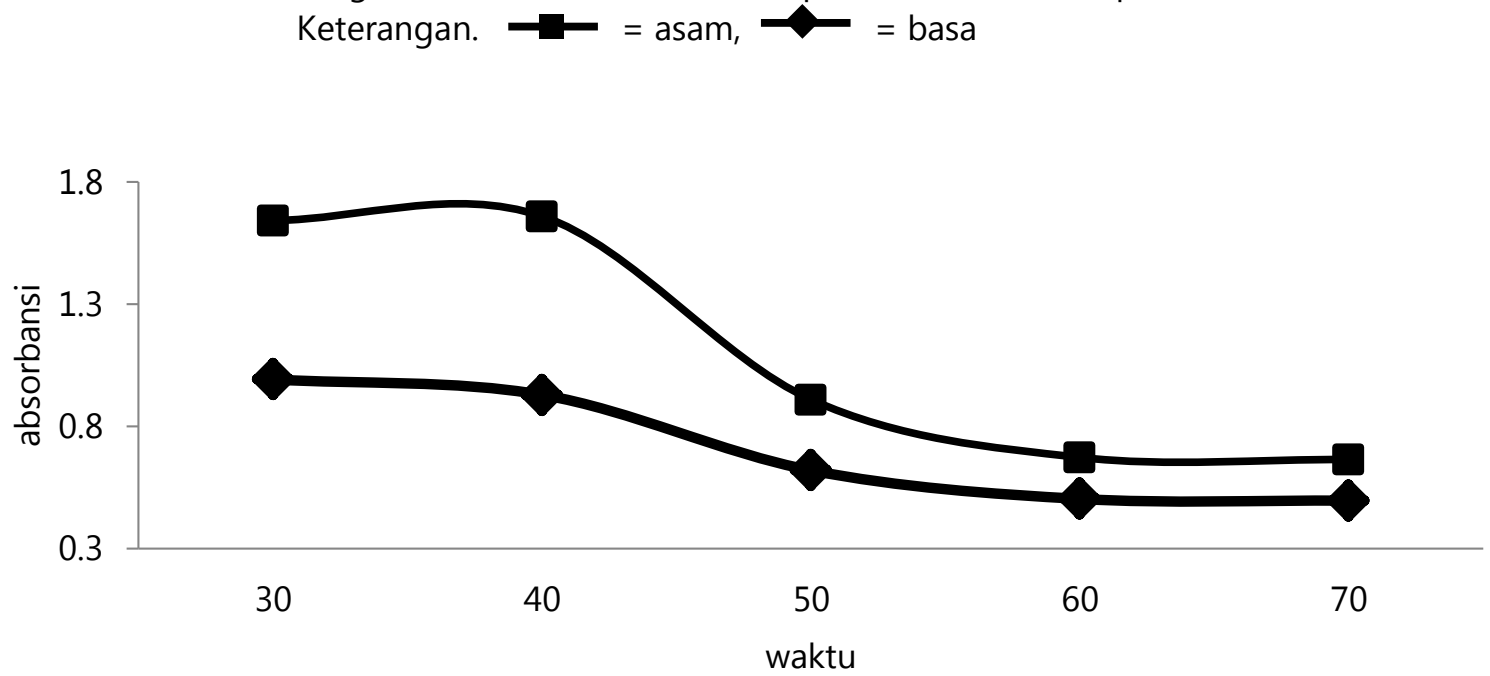

Gambar 4. Pengaruh PH terhadap absorbansi rafinat perbedaan waktu Keterangan. $\boldsymbol{T}=$ asam, $\boldsymbol{\sim}=$ basa

Pada hasil yang didapat juga pada suhu 55,60 dan 65 menunjukkan hasil absorbansi yang konstan hal ini membuktikan bahwa pH stabil maka klorofil yang tereduksi optimum juga akan stabil. Hasil ini menunjukkan sudah sesuai dengan teori bahwa $\mathrm{pH}$ mempengaruhi konsentrasi absorbansi pada uji analisa spektrofotometer (Senguttuvan et al., 2014).

Berdasarkan penelitian dengan perbedaan suhu hasil ekstraksi dengan 5 kali percobaan $\mathrm{pH}$ berbeda pada penambahan 1-5 tetes $\mathrm{NaOH} \mathrm{pH}$ basa dan $\mathrm{HCl} \mathrm{pH}$ asam dihasilkan pada penambahan $\mathrm{NaOH}$ yaitu $\mathrm{pH}$ menunjukkan $\mathrm{pH} 9$ ini menunjukkan bahwa pada $\mathrm{pH} 2$ dan 9 rafinat dapat mereduksi klorofil. Pada hasil yang didapat waktu ke 60 dan 70 menunjukkan nilai absorbansi dan penambahan $\mathrm{HCl} \mathrm{pH}$ menunjukkan 2, dikarenakan dengan menggunakan sampel hasil ekstraksi yang sama maka $\mathrm{pH}$ rafinat dan $\mathrm{pH}$ ekstrak juga sama (Gambar 4). Pada hal ini stabilitas $\mathrm{pH}$ asam dapat mereduksi klorofil pada $\mathrm{pH} 2$ menunjukkan hasil percobaan 630 menit 0,650, percobaan 740 menit 0,731 , percobaan 8 50 menit 0,290, percobaan 960 menit 0,170; dan percobaan 1070 menit 0,388, dan $\mathrm{pH}$ basa dapat mereduksi klorofil pada $\mathrm{pH} 9$ percobaan 630 menit 0,991, percobaan 740 menit 0,928, percobaan 850 menit 0,119 , percobaan 960 menit 0,502 dan percobaan 1070 menit 0,575. Hal yang relatif sama hal ini karena zat-zat klorofil yang banyak terbawa pelarut sehingga menjadi ekstak, maka zat klorofil yang terbawa ke rafinat 
hanya sedikit. Hal ini sudah sesuai teori bahwa $\mathrm{pH}$ yang stabil menjadikan nilai absorbansi yang sama (Sunanda, 2017).

\section{KESIMPULAN}

Stabilitas $\mathrm{pH}$ adalah suatu tanda $\mathrm{pH}$ menunjukkan $\mathrm{pH}$ yang stabil untuk mereduksi suatu klorofil sehingga dihasilkan panjang gelombang yang lebih sedikit. Tanaman mangga memiliki daun yang mengandung klorofil, klorofil tersebut di analisis kandungannya dengan warna hijau daun (klorofil) menggunakan spektrofotometri dipengaruhi oleh suhu ekstraksi, waktu ekstraksi dan penambahan solven. Pada kondisi optimum untuk menghasilkan jumlah kandungan klorofil tinggi pada daun mangga yang memiliki warna hijau lebih tua pada suhu $60^{\circ} \mathrm{C}$, dengan perbandingan solvent isopropil alkohol : air $=75 \%: 25 \%$, waktu 70 menit menghasilkan volume ekstrak 3,41 liter, volume rafinat 0,37 liter. . Hasil analisa dengan metode spektrofotometri menghasilkan absorbansi ekstrak $1,613 \mathrm{~nm}$; rafinat $0,517 \mathrm{~nm}$. Pada uji analisa stabilitas pada $\mathrm{pH} 2$ (suasana asam) menghasilkan absorbansi ekstrak 1,422 dan absorbansi rafinat $0,388 \mathrm{~nm}$. Selan utnya dilakukan uji analisa stabilitas pada $\mathrm{pH} 9$ (suasana basa) menghasilkan absorbansi ekstrak 1,919 nm dan absorbansi rafinat $0,575 \mathrm{~nm}$.

\section{DAFTAR PUSTAKA}

Andres, B.A., Barreto, P.V., Gracia, S.P., Mir-Bell, J. \& Martinez, M.J. 2013. Effect of $\mathrm{pH}$ on color and texture of food products. Food Engineering Reviews. 5:158-170. doi: 10.1007/s12393-013-9067-2

Arrohmah, A., Supriyanto, A. \& Kusumandari, K., 2007. Study of chlorophyll characteristic on leaves as photodetector organic material. Biofarmasi Journal of Natural Product Biochemistry, 5(2):67-72.

Ati, N.H., Rahayu, P., Notosoedarmo, S. \& Limantara, L., 2006. The Composition and The Content of Pigments from Some Dyeing Plant for Ikat Weaving in Timorrese Regency, East Nusa Tenggara. Indonesian Journal of Chemistry, 6(3), pp.325-331.
Casas, L., Mantell, C., Rodríguez, M., López, E. \& Martínez De La Ossa, E., 2009. Industrial design of multifunctional supercritical extraction plant for agro-food raw materials. Chemical Engineering Transactions, 17:15851590.

Chew, K.K., Khoo, M.Z., Ng, S.Y., Thoo, Y.Y., Aida, W.W. \& Ho, C.W., 2011. Effect of ethanol concentration, extraction time and extraction temperature on the recovery of phenolic compounds and antioxidant capacity of Orthosiphon stamineus extracts. International Food Research Journal, 18(4):1427-1435

Chonhenchob, V., Kamhangwong, D., Kruenate, J., Khongrat, K., Tangchantra, N., Wichai, U. \& Singh, S.P. 2011. Preharvest bagging with wavelength-selective materials enhances development and quality of mango (Mangifera indica L.) Journal of the Science of Food and Agriculture, 91(4):664-671.

Darma, W.X. \&Kito, K. 2014. Development of sago starch extractor with stirrer rotary blade for improving extraction performance. International Agricultural Engineering Journal, 6(5):2472-2481.

Milenković, S.M., Zvezdanović, J.B., Anđelković, T.D. \& Marković, D.Z., 2012. The identification of chlorophyll and its derivatives in the pigment mixtures: HPLC-chromatography, visible and mass spectroscopy studies. Adv Technol, 1:16-24.

Salisbury, F.B. \& Ross," C.W. 1995. Fisiologi Tumbuhan Jilid 1. Bandung: ITB

Sasmitamihardja, D. \& Siregar, A. 1997. Fisiologi tumbuhan. Jakarta: Depdiknas.

Senguttuvan, J., Paulsamy, S. \& Karthika, K., 2014. Phytochemical analysis and evaluation of leaf and root parts of the medicinal herb, Hypochaeris radicata L. for in vitro antioxidant activities. Asian Pacific journal of tropical biomedicine, 4:S359-S367.

Sumenda, L., 2011. Analisis kandungan klorofil daun mangga (Mangifera indica L.) pada tingkat perkembangan daun yang berbeda. Bioslogos, 1(1):20-24.

Putriantari, M. \& Santosa, E., 2014. Pertumbuhan dan Kadar Alkaloid Tanaman Leunca (Solanum americanum Miller) pada Beberapa 
Dosis Nitrogen. Jurnal Hortikultura Indonesia, 5(3):175-182.

Senguttuvan, J., Paulsamy, S. \& Karthika, K., 2014.

Phytochemical analysis and evaluation of leaf and root parts of the medicinal herb, Hypochaeris radicata L. for in vitro antioxidant activities. Asian Pacific journal of tropical biomedicine, 4:S359-S367. 